\title{
Psychosocial Effect on Career Concerns among Staff of the Department Of Petroleum Resources, Nigeria
}

\author{
Aramide, Olufemi Kunle ${ }^{1}$, Idowu, Sarah Olubunmi ${ }^{2}$, \\ Aderibigbe, John Kolawole ${ }^{3}$ \\ I'Department of General Studies/The Polytechnic, Ibadan, Nigeria) \\ ${ }^{2}$ (Department of Petroleum Resources, Nigeria) \\ ${ }_{3}^{3}$ Department of Learning and Development/Chartered Institute of Personnel Management, Nigeria)
}

\begin{abstract}
This study explored effect of error-strain, covering-up errors, gender and education on career concerns among staff of Department of Petroleum Resources, Nigeria. Quasi-experimental research design, purposive and convenience sampling techniques were adopted. 217 male and female staff participated. A questionnaire form was administered to participants. Three hypotheses were tested using univariate analysis of variance and t-test of Independent groups. Results showed that, covering-up errors significantly affected career concerns $F(3,213)=5.432 ; P<.05$. However, error-strain did not affect career concerns $F(3,213)=1.133$; $P>.05$. Furthermore, covering-up errors and error-strain did not have interaction effect on career concerns, $F$ $(3,213)=0.083 ; P>.05$. Female participants significantly scored higher on career concerns than male participants $(t=.07, d f(215) p<.05)$. Similarly, low educated staff significantly scored higher on career concerns than the high educated staff ( $t=3.52, d f(189) p<.05)$. Hence, it was concluded that, covering-up errors, gender and education are significant factors that affect career concerns among employees. Recommendation was given that managers should give more managerial attentions to female employees to help them match equally with their male counterparts on education and job related skills so that they feel comfortable with their chosen career.
\end{abstract}

Keywords: Career Concerns, Covering-up Errors, Education, Error-Strain and Gender.

\subsection{Nature of the Problem}

\section{Introduction}

Career concerns have become an issue of enormous interest to academics, practitioners, regulators, employers and employees in recent years. Career concerns are individual concerns about vocational feature. The most important function of career concerns is shaping careers. It entails worries about recent task failure, anxiety about a current tasks and excitement or stress of planning for a future task (Cairo, Kritis \&Myers, 1996). Code and Berners (2006) summarized career concerns as represent apprehension about managing what a person considers to be personally important and essential to his or her career development. In broad terms, career concerns relate to challenges experienced in one's career during various career stages. In other words, it relates to specific development tasks that are associated with specific stages in career development. However, to understand more about the phenomenon of career concerns this study, examined effect of error-strain, coveringup errors, gender and education on career concerns.

The construct of covering-up errors implies a strategy of anxious people who consider errors as a threat and, therefore prevent accusations often with errors in a social context. Error strain on the other hand means being distressed by making errors and therefore fearing the occurrence of errors or reacting to errors with high emotions. Errors are important issues in work psychology for various reasons. First, it is the raw material that produces stress, accidents, inefficient human and machine interaction, quality and performance problems, and bad climate. Second, attitudes towards error and how one deal with them are indications of a company's organizational culture.

In view of the above, it is not surprising, then, that "career problems" appear on the agenda of politicians, governments and social partners - more often, and more intensely. A special European Council, held in Lisbon during March 2000, agreed on a strategy emphasizing the importance of career concerns. Related to Nigeria economic situation, the ultimate goal is, within the new dispensation of democracy, to reform Nigeria economy into a better and admirable economy. Nigeria government policy strategy is only focusing on the establishment of a dynamic knowledge economy as we are having currently, but neglecting the importance of modernization of labour-management relations and the issue of employees' job security, in which the key phrases are "investment in people" and "social inclusion". The government and her social partners are not taking full responsibilities for an attractive "human-capital climate" as it ought to be. 
The transition to an effective labour-management relationship and a secured work-environment economy is another challenge for employers as this could influence the nature of the necessary competencies as well as the manner in which these competencies can be acquired. On the basis of an extensive literature review and research, Onstenk (1997) shows that an employee in a knowledge society must possess three crucial and basic competencies namely "what?" question (what knowledge and skill do I need to function well and relate effectively in the work environment, so that I can feel comfortable in the organization), "how?" question (thus, implementation of the knowledge and skills acquired for effective performance on the job), and the third requirement is that, the knowledge society demands of her employees that they are not able to answer the "what?" and "how?" questions, but also the "why?" question. Employees must be able to explain why they have to do their jobs professionally minimizing errors.

\subsection{Previous Work}

The literature on career concerns dates back to fama (1980), who argued that Career concerns could induce effort, and thereby circumvent explicit incentive pay. Holmstrom (1982), in formalizing this intuition, recognized that career concerns improved some agency problems and made others worse. Since then, many papers have applied the career concerns approach to managerial behavior.

Literature on career concerns has focused on ex ante risk choice (Scharfstein and stein (1990), Zwiebel (1995), Prendergast and Stole (1996), and Avery and Chevalier (1999)). Bjork, Hansen, Torstad and Hamilton (2007) discovered that nurses with a master's degree or other continuing education were more satisfied than those without additional education and older nurses were more satisfied with their career than those younger ones. In addition, nurses who had worked longer at the hospital were more satisfied with their job than nurses who had worked for a shorter period of time at the hospital.

In regards to marital status, Mroczek and Spiro (2005) found that married men have higher life satisfaction than the never married ones. Since life satisfaction is often positively attached to career satisfaction, thus it seemed fit to state that married men have higher career satisfaction than non-married ones. Gazioglu and Tansel (2006) found that individuals with higher level of education (e.g., degree and postgraduate degree or Alevel to O-level) have lower level of career concerns than individuals with lower levels of education. Gazioglu and Tansel also found a U-shape career satisfaction and age, and that married individuals have career concens than the unmarried ones, women are more satisfied with their career than men. In regards to age,

Okpara, Squillace, \& Erondu (2005) found that overall career issues rises progressively from academics under 35 years of age to professors at least 55 years of age. Mathieu and Zajac (1990) found that age, organizational tenure and career level are related constructs. Assuming some opportunity for advancement within the organization, older workers will tend to have greater organizational tenure and are likely to occupy higher positions than are younger and newly hired employees. Older workers and who have been with an organization longer will have invested more to the organization, thus, they have better promotional opportunities and pay, and most likely to feel satisfied with their career. Sarker et al. (2003) found that organizational tenure is significantly associated with overall career issues in that career concerns is constant for the first decade of the organizational tenure and would be begin to rise after that period.

Edmondson's (1996) research on errors in a medical setting revealed a positive relationship between the number of detected errors and team performance. It turned out that highly performing teams reported more errors (i.e. made more errors and/or were more willing to report them). Edmondson concluded that these teams had a better error climate, which allowed them to talk about errors, which in turn increased detection and correction. Edmondson's (1996) findings are in line with Rochlin's (1999) assertion that high performance should not be confused with the absence of errors. Rybowiak Garst, Frese and Batinic (1999) differentiated eight factors: communication about errors; analysis of errors; correction of errors; learning from errors; anticipation of errors; knowledge, acceptance and anticipation of risks; strain caused by errors (negative); and covering up errors (negative).

Previous studies have indicated that an error culture does exist in companies (Rybowiak, Garst, Frese and Batinic 1999; Van Dyck, 2000). Van Dyck (2000) developed an Error Culture Questionnaire and concluded that beliefs, attitudes, norms and behavioural approaches regarding errors could be shared and that error culture does exist. Dormann \& Frese, (1994) and Van Dyck, (2000) published results on the managing of error culture in organisations. Bear (1999) studied the influence of error management climate and psychological safety climate on the relationship between modern manufacturing practices and company performance. Other studies include error training and the role of goal orientation (Heimbeck, 1999), and the role of error culture on organisational performance (Van Dyck, et al., 2000).

Tomas, Melia, and Oliver (1999) employed path analysis to examine the effect of safety climate on accidents. Contrary to their expectations, safety climate did not have a direct effect on workers' safety behavior. Instead, organizational variables influenced group processes (supervisors' and co-workers' safety response), 
"which in turn influenced workers' safety attitudes and behaviors, usually reported as the 'main' direct cause of accidents".

Oliver, Cheyne, Tomas, and Cox (2002) collected data from a wide range of industrial sectors in the Valencia region of Spain using structured interviews and employed SEM to test models depicting the influence of organizational and individual variables on accidents. They found that individual level variables, including safe behavior and general health, mediated the indirect effects of the organizational variables. Stress, in particular, was an important mediator of both organizational and environmental variables.

\subsection{Purpose of Study}

The general purpose of the study was to determine and document findings on perceived career concerns among Department of Petroleum Resources Staff, particularly the effect of error strain, covering-up errors, education and gender on career concerns. The study specially investigated:

- The main and interaction effects of error strain and covering-up errors on career concerns

- The effect of gender on career concerns

- The effect of education on career concerns

\subsection{Contribution of the Study}

Fear, anxiety, worry, and disturb about one's future are common to a worker who perceived one threat or the other in his or her career, which could limit his ability to actualize his full potentials on the career. The source of threat is mostly related to unaware personality challenges of employee. This however, necessitated the need for this empirical investigation and professional suggestions as remedies for the identified personal problem of such affected worker. In view of the above, findings from this study would contribute greatly to the understanding of the relationship between error-strain and career-concerns of employee. Findings from this study would also facilitate the knowledge of personality factor of covering-up error as it relates to the phenomenon of career concerns. Also, findings from this study would enable individual employees to better cope with errors committed as a result of personal negligence or incompetence through suggested appropriate training instead of hiding under the shadow of sham and pride that could create worries and fear of future. Hence, knowledge gained in this study would provide the groundwork necessary for managers, trainers, lecturers, scholars and other stakeholders to better address the salient issues of consideration in this study and designed effective mechanism of helping affected employees to be rehabilitated and well adjusted to the work environment. Findings would as well open scholars' attention to the factors of error and its psychological effect on the well-being of workers hence, adds to the body of literature on career concerns.

\subsection{Statement of Hypotheses}

1. There will be a significant main and interaction effect of error strain and covering-up errors on career concerns.

2. Female participants will experience career concerns higher than their male counterparts.

3. Participants with lower educational qualification will experience career concerns than those with higher educational qualification.

\subsection{Research Design}

\section{Research Methodology}

Quasi-experimental research design was adopted in this study. This was considered appropriate because the study tested for the effect of the independent variables on the dependent variable by collection of data directly from respondents through the use of questionnaire, without any active manipulation of the variables and responses of participants. Variables involved in the study are error strain, covering up errors, gender, education and career concerns. Error-strain, covering-up errors, gender and education were the independent variables while the dependent variable was career concerns.

\subsection{Participants}

Two hundred and seventeen (217) staff of the Department of Petroleum Resources in Lagos and Ibadan Offices respectively participated in the study. One hundred and twenty-seven $(58.5 \%)$ were males and ninety $(41.5 \%)$ were females. One hundred and thirty-three $(61.3 \%)$ were single, eighty-three $(38.2 \%)$ were married and one $(0.5 \%)$ participant did not indicate his or status. Participants with SSCE/O'Level certificates were thirty-four (15.7\%), ND/NCE certificate fifty-one (23.5\%), First Degree certificate seventeen (7.8\%), Master Degree certificate fifty-three (24.4\%), others sixty-two (28.6\%). One hundred and sixteen $(53.5 \%)$ were Christians, seventy-six (35\%) were Islam, eleven (5.1\%) were Traditional, Others fourteen (6.5\%). Ninety-Six (44.2\%) indicated Administrative staff as their job status, fifty-seven (26.3\%) Senior Officer, thirty-eight $(17.5 \%)$ Secretary, three (1.4\%) Engineer, seven (3.2\%) Manage/Director, ten (4.6\%) Driver, three $(1.4 \%)$ 
Supervisor, three $(1.4 \%)$ did not indicate their job status. Eighty-three (38.2\%) were Yoruba, eighty-five (39.2\%) were Igbo, fifteen (6.9\%) were Hausa, thirty-four (15.7\%) Others. Participants aged ranged from 18 years $(0.5 \%)$ to 55 years $(1.8 \%)$.

\subsection{Instrumentation}

Instrument used in this study was questionnaire which included three developed scales of measurement: error strain scale, covering up errors scale and career concerns scale. The questionnaire includes some demographic information such age, gender, marital status, job status, ethnicity, educational background and religion in the Section A. Section B contains 8-item career concerns scale developed with 5-likerts response format by Lim. V. K. G. and Teo, T.S. H. (1999). Authors report cronbach's alpha reliability value of 0.90 for the scale. Participants who scored high on the scale had high level of career concerns while participants who scored low had low level of career concerns while study reports cronbach's alpha of 0.77 . Section C contains 5item error strain scale developed with 5-likerts response format by Rybowiak, V., Garst, H., Frese, and Batinic, B. (1999). Authors report cronbach's alpha reliability value of 0.79 for the scale. Participants who scored high on the scale had high level of error strain while participants who scored low had low level of error strain while study reports cronbach's alpha of 0.64. Section D contains 6-item covering up error scale developed with 5likerts response format by Rybowiak, V., Garst, H., Frese, and Batinic, B. (1999). Authors report cronbach's alpha reliability value of 0.78 for the scale. Participants who scored high on the scale had high level of covering up error while participants who scored low had low level of covering up error. This study reports cronbach's alpha of 0.87 .

\subsection{Procedure}

Involvement of participants in the study was sought through personal contact between researchers and individual participants. This enables researchers to tell participants what the research was about and help to gain their participants' cooperation. Researchers visited the Lagos office of the Department of Petroleum Resources, sought permission through the secretary before the staff were engaged in the filling of questionnaires. Three days were spent Lagos for that purpose. So, at the end of the third day researchers had given out about one hundred and seventy-nine questionnaires and retrieved one hundred and thirty-four. However, by the end of the following week while researchers were at Ibadan office of the aforementioned organisation, another twenty-five filled questionnaire came from Lagos through a follow up effort of a research assist in Lagos. Hence, another set of similar questionnaires were printed for the staff in Ibadan office. Researchers started administered and retrieved the questionnaires to the staff in Ibadan office within four days. Seventy-five questionnaires were administered to the staff in Ibadan. However, Fifty-eight was returned. The whole process lasted for three weeks. All participants were given equal chance of participation as it covers virtually all categories of Staff i.e. both senior and junior staff. At the end of the process, a total number of two hundred and seventeen well filled questionnaires were retrieved from participants.

\subsection{Statistics Analysis}

Data collected was analysed using T-test and ANOVA. Hypothesis one was analysed using univariate analysis of variance while hypotheses two and three were analysed with t-test of independent groups.

\section{Figures and Tables}

Results of statistical analysis of data collected based on the stated hypotheses are presented below: Hypothesis one stated that there would be a significant main and interaction effect of error strain and coveringup errors on career concerns was tested using univariate analysis of variance. Results are presented in summary table below.

TABLE 3.1 Summary Table of Univariate Analysis of Variance, Showing the Main and Interaction Effects of Error-Strain and Covering-Up Errors on Career Concerns.

\begin{tabular}{|l|l|l|l|l|l|}
\hline \multicolumn{1}{|c|}{ Source } & \multicolumn{1}{c|}{ SS } & \multicolumn{1}{c|}{ df } & MS & F & Sig. \\
\hline Covering-up Errors & 93.07 & 1 & 93.07 & 5.432 & $<.05$ \\
\hline Error Strain & 19.404 & 1 & 19.40 & 1.133 & $>.05$ \\
\hline Covering-up Errors* Error Strain & 1.422 & 1 & 1.422 & .083 & $>.05$ \\
\hline Error & 3649.322 & 213 & 17.133 & & \\
\hline Total & 130908.000 & 217 & & & \\
\hline
\end{tabular}

Results in the table 3.1 above show that, there is a significant main influence of covering-up errors on career concerns $\mathrm{F}(3,213)=5.432 ; \mathrm{P}<.05$. However, It further shows that, there is no significant main effect of errorstrain on career concerns F $(3,213)=1.133 ; \mathrm{P}>.05$. Similarly, there is no significant interaction effect of 
covering-up errors and error-strain on career concerns, F $(3,213)=.083 ; \mathrm{P}>.05$. Therefore, hypothesis one was partially confirmed.

Hypothesis two on the other hand, which stated that female staff would experience career concerns higher than male staff, was tested using t-test of independent samples. Result is presented in the summary table two below.

TABLE 3.2: Summary of T-test of Independent Samples Showing the Mean Difference between Female and Male on Career Concerns.

\begin{tabular}{|l|l|l|l|l|l|l|l|}
\hline & Sex & $\mathbf{N}$ & $\mathbf{( X )}$ & $\mathbf{S D}$ & $\mathbf{D f}$ & $\mathbf{T}$ & $\mathbf{P}$ \\
\hline \multirow{4}{*}{ Career Concerns } & Male & 127 & 24.22 & 3.96 & \multirow{3}{*}{175} & \multirow{2}{*}{.07} & \\
\cline { 2 - 7 } & Female & 90 & 28.17 & 4.91 & & & \\
\hline
\end{tabular}

Results in the table 3.2 above show that female participants significantly scored higher on career concerns than male participants $(\mathrm{t}=.07$, df $(215) \mathrm{p}<.05)$. Therefore, hypothesis two, which stated that female staff will experience career concerns higher than male staff was confirmed.

Hypothesis three which stated that, staff with lower educational qualification would experience career concerns more than those with higher educational qualification, was tested using t-test of independent samples. Result is presented in summary table three below.

TABLE 3.3: Summary of T-test of Independent Samples Showing the Mean Difference between Highly Educated and Low Education Staff on Career Concerns.

\begin{tabular}{|c|c|c|c|c|c|c|c|}
\hline & Education & $\mathbf{N}$ & $(\mathbf{X )}$ & SD & Df & $\mathbf{T}$ & $\mathbf{P}$ \\
\hline \multirow{2}{*}{ Career Concerns } & High & 132 & 23.43 & 4.21 & \multirow{2}{*}{189} & \multirow{2}{*}{3.52} & \multirow{2}{*}{$<.05$} \\
\hline & Low & 85 & 25.40 & 3.87 & & & \\
\hline
\end{tabular}

Results in the table 3.3 above show that low educated staff significantly scored higher on career concerns than high educated staff $(\mathrm{t}=3.52$, df $(189) \mathrm{p}<.05)$. Therefore, hypothesis three, which stated that staff with lower educational qualification would experience career concerns than those with higher educational qualification, was confirmed.

\subsection{Discussion}

\section{CONCLUSION}

This study had been carried out to evaluate the effect of error-strain, covering-up errors, gender and education on career concerns of the Department of Petroleum Resources Staff. Three hypotheses were tested in the course of the study. This study found that hypothesis one, which stated that there would be a significant main and interaction effect of error-strain and covering-up errors on career concerns was partially confirmed. This implies that only the main effect of covering-up errors was significant on career concerns. Error-strain did not have significant effect on career concerns. Also, results revealed that there was no significant interaction effect of error-strain and covering-up errors on career concerns. These results further imply that the covering-up errors when combined with error-strain might not significantly affect employee's concerns. Error is an inevitable phenomenon. It could occur to anybody whether experienced or not, expert or an amateur. The common say "nobody is above mistake, or nobody is perfect" is confirmed in this study. Results of this study have established the fact that certain level of error cannot and should not cause a state of tension over one's career. A moderate amount of error is allowed on a difficult task. This creates rooms for development on the job not necessarily causing career problems such as career concerns. Edmondson's (1996) research on errors in a medical setting revealed a positive relationship between the number of detected errors and team performance. It turned out that highly performing teams reported more errors (i.e. made more errors and/or were more willing to report them). Edmondson concluded that these teams had a better error climate, which allowed them to talk about errors, which in turn increased detection and correction. Edmondson's (1996) findings are in line with Rochlin's (1999) assertion that high performance should not be confused with the absence of errors.

This study also found that hypothesis two, which stated that female staff would experience career concerns higher than male staff was confirmed. Female employees actually scored higher on career concerns than the male staff. Hence, female employees were noticed to had expressed higher career concerns than males. This could be because female individuals are said to be more emotional in analyzing situations most especially events around them which, could pose a threat to their careers. Furthermore, the trend of development in the world of work which exposes women to more challenges at work could have set in inherent fear about women's ability to deliver up to the level of expectation. This therefore has a way of affecting women psychologically 
and career wise. In respect of this, Mroczek and Spiro (2005) found that men have higher career satisfaction than the women. Also, Mathieu and Zajac (1990) found that age, gender, organizational tenure and career level are related constructs.

This study finally found that hypothesis was confirmed. This implies that employees who are less educated are more prone to psychological problems such as tension, dissatisfaction, fear, anxiety and doubt about his or her prospect on a particular career than more educated employees. This results further explains the effect of education on employees self-worth, efficacy, resiliency, hope, and satisfaction with their behaviors or occurrences, since education gave them better ability to constructively analyse situations such that makes them to do necessary adjustment as and when due to issues arising and therefore, effectively cope. Highly educated individuals could use their certificate to find employment opportunities to other areas of careers or job if they perceived the former not suitable. However, reverse is the case for the low educated employees who have no option than to stay on the career despite several complaints etc. Gazioglu and Tansel (2006) found that individuals with higher level of education (e.g., degree and postgraduate degree or A-level to O-level) have lower level of career concerns than individuals with lower levels of education.

\subsection{Conclusion}

It was therefore concluded in this study based on the findings above that:

1. Covering-up errors is a significant factor on career concerns.

2. Gender is a significantly factor on career concerns.

3. Education is a significant factor on career concerns.

\subsection{Recommendations}

Based on the above conclusions, it was therefore recommended that, government executives and private managers should effectively manage areas of differences across individual employees such that will bring about efficient pool of highly motivated employees. Managers should give adequate managerial attentions to female employees and help them to match equally with their male counterparts. Social and moral support should be given to female employees more than they enjoyed initially.Government executives and private managers should assigned larger portion of the corporate budget on educating the low educated employees as this will be better returns to the corporate bodies in terms of higher performance.

\subsection{Limitation of the Study}

The following challenges were faced in this course of this study:

- Administration of questionnaire was limited to Ibadan and Lagos offices of Department of Petroleum Resources.

- The time allotted to this study was short considering the nature of work of the participants and what the study was set out to achieve.

- Some participants did not fill or return the given questionnaire therefore, limited the number of questionnaire collected.

\subsection{Suggestions for Further Studies.}

This study examined only the effect of covering-up errors, error-strain, gender and education among. Other effective psychological and sociological variables were not included did. Researchers therefore, call on subsequent studies in this area draw variables that are not only psychological but include environmental, social, economic, political factors.

\section{REFERENCES}

[1] Cairo, P. C., Kritis, K. J., and Myers, R. M. (1996). Career assessment and the adult career concerns inventory. Journal of Career Assessment, 4, 189-204.

[2] Code, M., and Bernes, K. (2006). Adolescents' perceptions of career concerns. The National Consultation on Career Development (NATCON).

[3] Lisbon European Council (2000). European Parliament.

[4] Onstenk, J. (1997). Learning and Working - Broad Skills and the Integration of Learning, Working and Innovating. Delft: Eburon. (in Dutch).

[5] Dormann, T., \& Frese, M. (1994). Error training: Replication and the function of exploratory behavior. International Journal of Human-Computer Interaction, 6, 365-372.

[6] Scharfstein, David, and Jeremy Stein, (1990), Herd behavior and investment, American Economic Review 80, 465-79.

[7] Zwiebel, Jeffrey, (1995), Corporate conservatism and relative compensation, Journal of Political Economy 103, 1-25.

[8] Prendergast, Canice, and Lars Stole, (1996), Impetuous youngsters and jaded old timers: acquiring a reputation for learning, Journal of Political Economy 104, 1105-1134.

[9] Avery, Christopher, and Judith Chevalier, (1999), Herding over the career, Economics Letters 63, 327-33.

[10] Okpara, J.O., Squillace, M. \& Erondu, E.A. (2005). Gender differences and job satisfaction: A study of university teachers in the United States. Women in Management Review, 20(3), 177-190. 
[11] Rochlin, G. I. (1999). Safe operation as a social construct. Ergonomics, 42, 1549-1560.Rybowiak, V., Garst, H., Frese, M., \& Batinic, B. (1999). Error orientation questionnaire (E.O.Q.): Reliability, validity, and different language equivalence. Journal of Organizational Behavior, 20, 527, 547.

[12] Van Dyck, C. (2000). Putting error to good use: Error management culture in organizations. Unpublished Doctoral dissertation, The Vrije Universiteit, Amsterdam, The Netherlands.

[13] Heimbeck, D. (1999). Error training and the role of goal orientation. In Training and Motivation: The Function of Implementation Intentions, Goal Orientation and Errors for Performance. Doctoral dissertation, University of Amsterdam, Amsterdam, The Netherlands.

[14] Fama, E. F. (1980). Agency Problems and the Theory of the Firm. Journal of Political Economy, 88(2), 288-307.

[15] Holmstrom, Bengt, (1982), Managerial incentive problems - a dynamic perspective, Essays in Economics and Management in Honor of Lars Wahlbeck (Helsinki: Swedish School of Economics, 1982).

[16] Bjork I.T. Hansen, B.S, Torstad, S, and Hamilton G.A (2007). Job satisfaction in a Norwegian population of nurses: a questionnaire survey. International Journal of Nursing Studies. 44, 5, 747-757.

[17] Mroczek, D.K. and Spiro, A, III (2005). Change in life satisfaction over 20 years during adulthood: Findings from the VA Normative Aging Study. Journal of Personality and Social Psychology, 88, 189-202.

[18] Gazioglu, S. and Tansel, A. (2006), "Job satisfaction in Britain: Individual and job relatedfactors", Applied Economics, 38: $1163-71$.

[19] Mathieu, J., and Zajac, D. (1990). A review and meta-analysis of the antecedents, correlates, and consequences of organizational commitment. Psychological Bulletin, 108(2), 171-194.

[20] Sarker, S.J., Crossman, A. and Chinmeteepituck, P. (2003). The relationships of age and length of service with job satisfaction: an examination of hotel employees in Thailand. Journal of Managerial Psychology, 18(7): 745-758.

[21] Edmondson, A. C. 1996. Learning from mistakes is easier said than done: Group and organizational influences on the detection and correction of human error. The Journalof Applied Behavioral Science, 32(1): 5.

[22] Bear, M. (1999). The influence of error management climate, and psychological safety climate on the relationship between modern manufacturing practices and company performance. Master's Thesis, University of Giessen, Giessen, Germany.

[23] Tomás, J. M., Melia, J. L., \& Oliver, A. (1999). A cross-validation of a structural equation model of accidents: Organizational and psychological variables as predictors of work safety. Work and Stress, 13, 49-58.

[24] Oliver, A., Cheyne, A., Tomás, J. M., \& Cox, S. (2002). The effects of organizational and individual factors on occupational accidents. Journal of Occupational and Organizational Psychology, 75, 473-488. 